\title{
The long-acting somatostatin analogue octreotide alleviates symptoms by reducing posttranslational conversion of prepro-glucagon to glucagon in a patient with malignant glucagonoma, but does not prevent tumor growth
}

\author{
F. Jockenhövel ${ }^{1}$, S. Lederbogen ${ }^{1}$, T. Olbricht ${ }^{1}$, H. Schmidt-Gayk ${ }^{2}$, E.P. Krenning ${ }^{3}$, S.W.J. Lamberts ${ }^{4}$, \\ D. Reinwein ${ }^{1}$ \\ ${ }^{1}$ Abteilung für Klinische Endokrinologie, Medizinische Klinik und Poliklinik der Universität, \\ Hufelandstrasse 55, D-45122 Essen, Germany \\ ${ }^{2}$ Endokrinologisches Labor, Laborärztliche Gemeinschaftspraxis, D-69126 Heidelberg, Germany \\ ${ }^{3}$ Department of Nuclearmedicine, Erasmus University, NL-3015 GD Rotterdam, The Netherlands \\ ${ }^{4}$ Department of Internal Medicine III, Erasmus University, NL-3015 GD Rotterdam, The Netherlands
}

Received: 18 September 1993 / Accepted: 12 October 1993

\begin{abstract}
A 52-year-old female with metastatic glucagonoma secreting glucagon and chromogranin A was treated with the somatostatin analogue octreotide for 2 years without any additional tumor-reducing interventions. Before therapy plasma glucagon was above $8 \mu \mathrm{g} / 1$ (normal $<0.2$ ) and within 2 days $3 \times 200 \mu \mathrm{g}$ octreotide daily suppressed plasma glucagon to $2.2-2.5 \mu \mathrm{g} / 1$. Concomitantly, chromogranin A dropped from $0.85 \mathrm{mg} / 1$ (normal <0.1) to 0.2 . After 3 weeks the preexisting disabling necrolytic migratory erythema had vanished completely, and weight loss was temporarily stopped. During therapy chromogranin A and plasma glucagon rose, exceeding pretreatment levels after 3 and 14 months, respectively. After 1 year the erythema recurred, responding only transiently to increasing doses of octreotide. The patient died after 2 years of therapy of tumor cachexy despite very high doses of octreotide $(4 \times 600 \mu \mathrm{g} /$ day $)$. Throughout treatment octreotide did not prevent tumor growth, as demonstrated by computed tomography and sonography. Determination of immunoreactive glucagon before and during octreotide therapy in fractions of plasma samples subjected to gel chromatography revealed a reduction in the ratio of glucagon to preproglucagon from 1.83 (before) to 0.56 (during therapy), indicating inhibition of posttranslational processing of preproglucagon by octreotide, thereby reducing circulating bioactive glucagon. In summary, oc-
\end{abstract}

Abbreviations: $\mathrm{CGA}=$ chromogranin $\mathrm{A} ; \mathrm{IRG}=$ immunoreactive glucagon; $\mathrm{OC}=$ octreotide

Correspondence to: D. Reinwein treotide induced a remission of clinical symptoms by inhibiting posttranslational conversion of preproglucagon to glucagon but did not prevent tumor growth. Therefore, octreotide is a valuable therapy for rapid relief of clinical symptoms, thereby improving the possibilities for other tumor-reducing therapies.

Key words: Glucagon - Glucagonoma - Octreotide - Chromogranin A - Preglucagon - Preproglucagon - Somatostatin

Glucagonomas are rare tumors of the pancreatic alpha cells, with fewer than 150 patients reported [13]. Whereas the combination of the clinical symptoms (necrolytic migratory erythema, hyperglycemia, normochromic normocytic anemia, and weight loss) are typical for a glucagonoma and thus have been termed glucagonoma syndrome [5], the symptoms are rather unspecific when considered individually. This often delays correct diagnosis until the tumor has progressed to a considerable size, with local invasion and liver metastases being a common finding [13]. Complete surgical removal of the tumor cannot be achieved in most patients, and chemotherapy is frequently ineffective $[9,13$, 18]. Recently somatostatin and its long-acting analogue octreotide (OC) have been introduced for conservative management of endocrine-active gastrointestinal tumors. So far five patients with glucagonoma have been treated with OC for 1 year or longer $[1,21,30]$. Interestingly, all patients expe- 
rienced clinical improvement, despite elevated glucagon plasma levels during therapy. We report our experiences in the long-term treatment of a patient with malignant glucagonoma and propose a mechanism by which OC induces clinical remission of symptoms.

\section{Case report}

In a 51-year-old white woman complaining of epigastric pain abdominal ultrasound and computed tomography identified a tumor in the pancreatic head and metastases in the liver. Simultaneously hyperglycemia, weight loss of $6 \mathrm{~kg}$, and the onset of a cutaneous rash was noted. Laparatomy (Fig. 1, day 122$)$ revealed a tumor $(3 \times 4 \mathrm{~cm})$ in the pancreatic head and several metastases in the right and left lobes of the liver. Except for a small nodule on the surface of left lobe of the liver no tissue was removed. Histological and immunocytochemical examination revealed a pancreatic alpha cell tumor staining positive for glucagon and chromogranin A (CGA). Glucagon plasma levels, determined postoperatively, were extremely elevated $(7.8-8.3 \mu \mathrm{g} / 1)$. Thereafter the patient's condition gradually deteriorated, with further weight loss (Fig. 1F), development of normochromic normocytic anemia (Fig. 1C) and rapid spreading of the rash. In July 1990 the patient was referred to our clinic for further therapy.

We saw a mildly depressed lady of normal weight (height $164 \mathrm{~cm}$, weight $59.5 \mathrm{~kg}$ ) with disseminated desquamating pruritic rash, most pronounced in areas of mechanical friction. Severe cheilitis and stomatitis prevented intake of regular food. Histological examination of a skin biopsy confirmed necrolytic migratory erythema. After detailed information about the nature of the disease the patient rejected laparatomy for palliative reduction of tumor mass as well as any form of cytostatic chemotherapy but gave written informed consent to participate in the German Multicenter Trial for Therapy of Endocrine Gastrointestinal Tumors with Octreotide which had been approved by the Ethics Committee of the Philipps-University, Marburg, Germany (study center). After obtaining baseline data, including an oral glucose tolerance test revealing nonsuppressible glucagon levels, therapy with OC (Sandostatin, Sandoz, Nürnberg, Germany) was initiated on day 1 (Fig. 1E). To avoid hypoglycemic reactions, OC was given in incremental doses $(3 \times 50 \mu \mathrm{g} /$ day for 3 days, $3 \times 100 \mu \mathrm{g} /$ day for 3 days) until the maintenance dose of $3 \times 200 \mu \mathrm{g} /$ day was reached.

Pathological laboratory findings on admission were as follows (normal values in parentheses): hemoglobin $98 \mathrm{~g} / 1$ (120-160), fasting blood glucose $11.7 \mathrm{mmol} / 1 \quad(<5.55)$, glycosylated hemoglobin $10.4 \%(<8 \%)$, glucagon $8.43 \mu \mathrm{g} / 1 \quad(<0.2)$, insulin $21 \mathrm{mIU} / 1$, C peptide $5.0 \mathrm{ng} / \mathrm{ml}$, CGA $0.85 \mathrm{mg} / 1$ $(<0.1)$. All other investigations revealed normal values.

\section{Material and methods}

Blood samples were obtained in chilled tubes containing EDTA and $500 \mathrm{U}$ aprotinin (Trasylol, Bayer, Leverkusen, Germany) per milliliter of blood. After centrifugation at $4^{\circ} \mathrm{C}$ and $2500 \mathrm{rpm}$ for $20 \mathrm{~min}$, the plasma was immediately separated and stored at $-20^{\circ} \mathrm{C}$ until assayed. Plasma samples were analyzed using a commercially available assay for glucagon employing a rabbit antiglucagon antibody $(100 \%$ cross-reaction with preproglucagon and proglucagon) and polyethylenglycol for separation of bound from free (Serono Diagnostica, Freiburg, Germany). Intra- and interassay $(n=6)$ coefficients of variation were $5.6 \%$ and $7.8 \%$, respectively.

CGA was determined in serum samples with an immunoluminometric assay described elsewhere [4]. Intra- and interassay coefficients of variation were $5.5 \%$ and $12.6 \%$, respectively.

Plasma samples were placed on polyacrylamide gel (Bio-Gel P-30, Bio-Rad Laboratories, Richmond, CA, USA), column size $1 \times 50 \mathrm{~cm}$, and eluted with $0.2 \mathrm{~mol} / \mathrm{l}$ glycine (Sigma Diagnostics, St. Louis, MO, USA) containing $0.25 \%$ human serum albumin (Sigma Diagnostics), $500 \mathrm{U}$ aprotinin/1, and $1 \%$ normal sheep serum, $\mathrm{pH} 8.8$, at $4^{\circ} \mathrm{C}[7,24$, 25]. The flow rate was $5 \mathrm{ml} / \mathrm{h}$. The column was calibrated with dextran blue, ribonuclease $\mathrm{A}$, cytochrome $c$, cobalamine (all Sigma Diagnostics) and tracer amounts of ${ }^{125} \mathrm{I}$-labeled $\mathrm{C}$ peptide and ${ }^{125} \mathrm{I}$-labeled insulin. ${ }^{125} \mathrm{I}$-labeled glucagon was added to each run. Eluates of $1.5 \mathrm{ml}$ were collected, counted for radioactivity, and analyzed for glucagon immunoreactivity (IRG). IRG was determined using antiserum $30 \mathrm{~K}$ (kindly provided by Prof. R.H. Unger) and dextran coated charcoal separation following previously published methods [10]. All samples were analyzed in one assay. The coefficient of variation was $11.4 \%$.

Scintigraphy with labeled OC was performed after interruption of $\mathrm{OC}$ therapy for 8 days (days $65-73$, Fig. 1E) The radiopharmaceutical $\left[{ }^{111} \mathrm{In}-\right.$ DTPA-D-Phe ${ }^{1}$-OC and imaging procedure have been described previously $[3,15]$.

The size of the primary tumor in the head of the pancreas and a reference metastasis were deter- 
mined by computed tomography and ultrasonography. The largest diameters of three axes vertical to each other were determined, multiplied, and expressed as tumor size in milliliters. Computed tomography and ultrasonography performed before day 5 were made with different equipment, but pictures and scans were available for evaluation.

\section{Results}

\section{Clinical course}

Throughout therapy $O C$ did not inhibit tumor growth (Fig. 1A). Due to compression of the duodenum between the primary tumor and a large liver metastasis causing postprandial vomiting and cholestasis laparatomy with gastrojejunostomy and a biliodigestive anastomosis had to be performed on day 422 of therapy.

Plasma glucagon levels were grossly elevated before therapy and dropped to $2.2-2.5 \mu \mathrm{g} / 1$ within 2 days after initiation of OC therapy (Fig. 1E). When OC was discontinued for 8 days, a rapid increase was observed, with the peak $(9.39 \mu \mathrm{g} / \mathrm{l})$ exceeding pretreatment levels. After reinstitution of OC treatment, the glucagon plasma levels were suppressed to the previous treatment range.

During the initial phase of OC treatment serum CGA was suppressed to $0.2-0.5 \mathrm{mg} / 1$ (Fig. 1D). CGA increased rapidly to above pretreatment levels during $\mathrm{OC}$ discontinuation and was quickly suppressed when $O C$ was reinstituted. From then on a constant slow rise in both tumor products, glucagon and CGA, was observed, except for a sudden increase in glucagon after 400 days of therapy, which appears to be related to the rapidly growing liver metastasis.

The severely handicapping necrolytic migratory erythema improved within 3 days of OC treatment and completely resolved after 21 days of therapy, as did the stomatitis and cheilitis. When therapy was interrupted for 8 days for scintigraphy with labeled OC, early signs of the rash were noticed, which quickly responded to the continuation of therapy. On day 140 the patient noticed recurrence of the rash, which from then onward waned and recurred despite continued therapy with OC. After day 400 the rash occurred frequently and improved only temporarily in response to increasing OC doses (Fig. 1E). On day 562 the necrolytic migratory erythema had considerably worsened, requiring hospitalization, and did not improve despite intensified therapy with $\mathrm{OC}(4 \times 600 \mu \mathrm{g} /$ day $)$.

After initiation of $\mathrm{OC}$ therapy and one package of erythrocytes $(450 \mathrm{ml})$ serum hemoglobin concen-

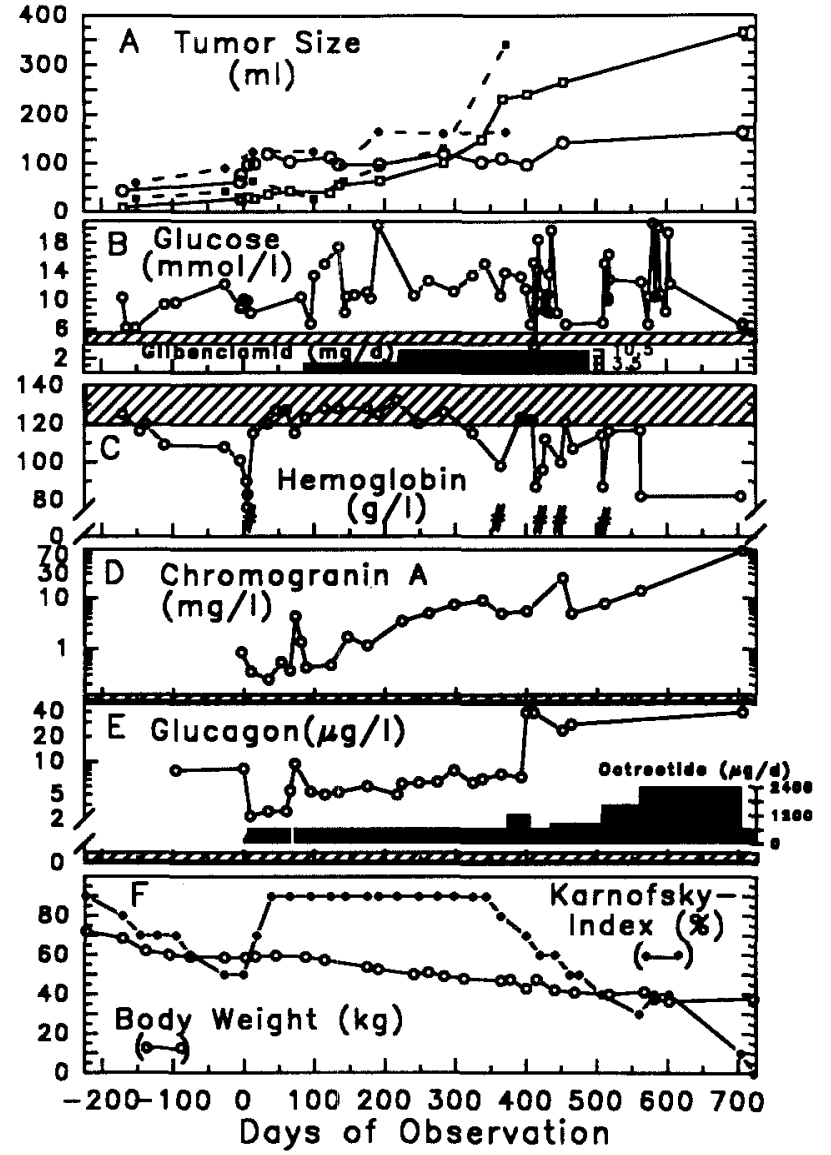

Fig. 1. Synopsis of clinical data (tumor size, A; body weight, F; Karnofsky index, F) and laboratory data (fasting blood glucose, B; haemoglobin, C; serum chromogranin A, D; plasma glucagon, E) of the glucagonoma patient before and during therapy with $\mathrm{OC}$, which was initiated on day 1 (doses of $\mathrm{OC}$ are depicted in $\mathbf{E}$ ). The size of the primary tumor in the pancreatic head (circles) and of a reference metastasis in the right liver lobe (squares) were determined by ultrasonography (open symbols) and computed tomography (solid symbols A). Supplementation with erythrocyte concentrates $(450 \mathrm{ml})$ is indicated $(\#, C)$. Where applicable, normal ranges are shaded. Note the logarithmic scales in $\mathbf{D}$ and $\mathbf{E}$

trations showed a rapid increase (Fig. 1C). Hemoglobin levels stabilized thereafter in the lower normal range. The surgery-related blood loss after day 422 required transfusions of erythrocytes $(2 \times$ $450 \mathrm{ml}$ ).

Fasting blood glucose worsened during therapy with OC (Fig. 1B). Whereas before treatment with $\mathrm{OC}$ fasting glucose rarely exceeded $10 \mathrm{mmol} / \mathrm{l}$, during therapy it was usually around $12 \mathrm{mmol} / \mathrm{l}$. The oral antidiabetic glibenclamide lowered blood glucose concentrations but was unable to normalize glucose levels. The patient refused insulin therapy since this required subcutaneous injections in addition to $\mathrm{OC}$. 
Body weight, which had decreased by more than $20 \%$ within 7 months, increased slightly with initiation of OC therapy, but after 3 months the weight loss continued (Fig. 1F). Repeated intermittent high-caloric parenteral nutrition $(>21 \mathrm{~kJ}$ per day) supplemented with human insulin was unable to prevent further weight loss. After 2 years of therapy the patient died of cachexy, with a body weight of $38.3 \mathrm{~kg}$.

In addition to other parameters in Fig. 1, the Karnofsky index [14] presents the clinical improvement induced by OC therapy (Fig. 1F). Within a few weeks after initiation of treatment, the patient improved remarkably and was able to live at home without additional support. After 1 year of therapy the symptoms caused by the duodenal stenosis and cholestasis initiated a continuous decline in the Karnofsky index. Since the patient rejected both surgical tumor reduction and any form of chemotherapy, OC therapy was continued after day 450 despite clinical and laboratory signs of tumor progression.

\section{Side effects}

Throughout the treatment with $\mathrm{OC}$ the patient experienced slight pain at the injection site lasting for several minutes. OC enhanced a preexisting tendency to loose stools and induced steatorrhea, which was not improved by supplementation of pancreatic enzymes or treatment with loperamide. After 3 months of $\mathrm{OC}$ therapy fasting glucose serum levels were increased but improved on therapy with glibenclamide. Gall bladder stones did not develop.

\section{Gel chromatography of plasma glucagon}

Gel chromatographic separation with subsequent determination of IRG of a plasma sample obtained before OC therapy clearly showed three distinct peaks, with molecular weights of 3500,9000 , and greater than 13000 daltons (Fig. 2). Analysis of a plasma sample obtained when glucagon levels were

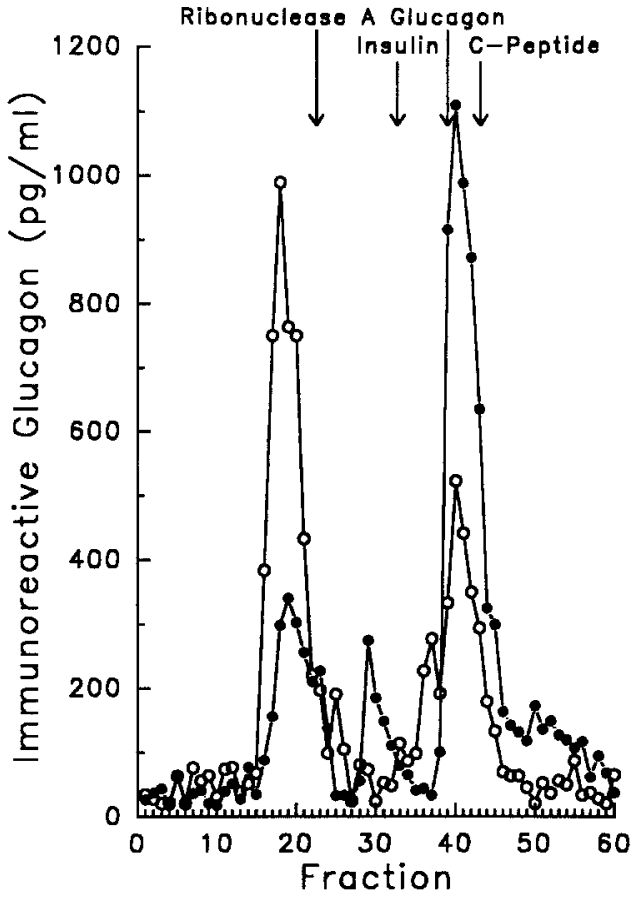

Fig. 2. Determination of immunoreactive glucagon in plasma samples obtained before $(\mathbf{O})$ and during $(\bigcirc)$ therapy with $O C$ submitted to gel chromatography. Fractions $15-25$ are proposed to resemble preproglucagon, fractions 27-33 proglucagon, and fractions 37-46 glucagon

suppressed to $2.49 \mu \mathrm{g} / 1$ after 60 days of OC therapy revealed only two peaks of IRG, of 3500 and greater than 13000 daltons (Fig. 2). The ratio of the relative amount of IRG in fractions containing the different peaks was reversed by OC therapy (Table 1). In addition, during therapy with $\mathrm{OC}$ no substantial peak for proglucagon was observed.

\section{Somatostatin scintigraphy}

Figure 3 illustrates the primary tumor in the head of the pancreas and its metastasis in the liver $48 \mathrm{~h}$ after intravenous injection of $320 \mathrm{MBq}\left[{ }^{111} \mathrm{In}-\mathrm{DT}\right.$ PA-D-Phe ${ }^{1}$-OC. Other sites of metastasis were not observed.

Table 1. Relative proportion of IRG of different fractions of plasma samples obtained before and during therapy with $\mathrm{OC}$ (day 60) after submission to gelchromatography (Fig. 2)

\begin{tabular}{llcc}
\hline Fractions & Peptide & $\begin{array}{l}\text { Before therapy } \\
\text { (\% of IRG) }\end{array}$ & $\begin{array}{l}\text { During therapy } \\
\text { (\% of IRG) }\end{array}$ \\
\hline $15-25$ & Preproglucagon & 24.5 & 56.7 \\
$27-33$ & Proglucagon & 9.8 & 4.7 \\
$37-46$ & Glucagon & 62.6 & 34.5 \\
$15-46$ & & 100 & 100 \\
\hline
\end{tabular}



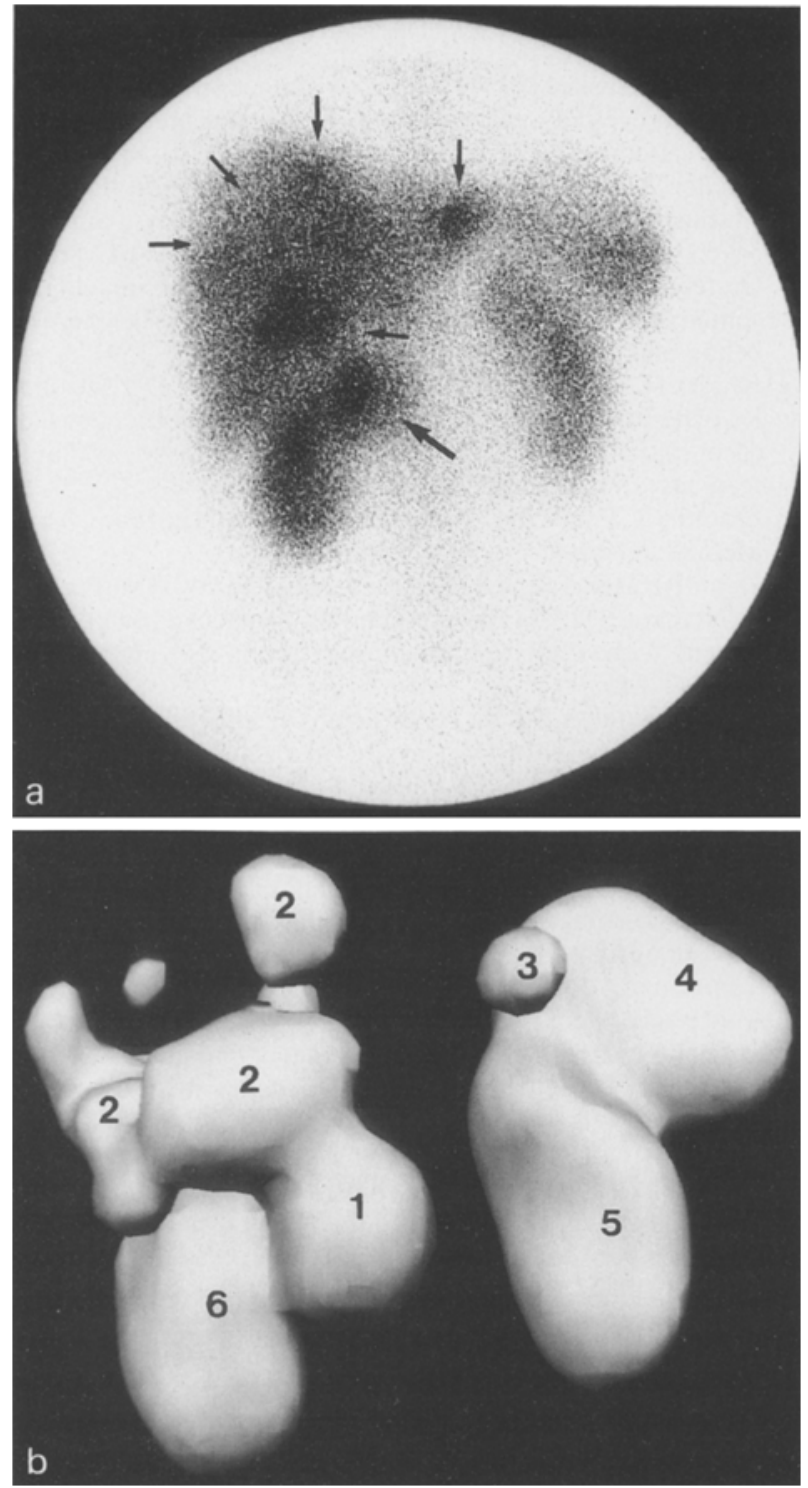

Fig. 3A, B. Abdominal image in a patient with glucagonoma, $48 \mathrm{~h}$ after injection of ${ }^{111}$ In-labeled OC. A Anterior planar image. Normal uptake of radioactivity in the kidneys and spleen. The various hot spots in the liver indicate the presence of metastasis of the primary tumor, which is located directly medial to the upper pole of the right kidney. B Three-dimensional reconstruction. Liver background has been reduced. The kidneys and spleen are visualized. The primary tumor in the head of the pancreas and its metastasis in the liver are also visualized. 1, Primary tumor in the pancreatic head; 2 , metastasis in the right lobe of the liver; 3 , metastasis in the left lobe of the liver; 4 , spleen; 5, left kidney; 6, right kidney

\section{Discussion}

The long-acting somatostatin analogue $\mathrm{OC}$ has been used in a variety of endocrine tumors for suppression of hormone production and secretion $[8$, 17], but few patients with glucagonoma have been studied during long-term therapy with somatostatin alone $[1,21,30]$. In our patient OC initially induced a lasting remission of clinical symptoms but did not inhibit tumor growth. The remarkably quick resolution of the previously disabling necrolytic migratory erythema improved the well-being of the patient within few days. Furthermore, the hemoglobin concentration was normalized without additional therapy within 4 weeks of therapy. This patient gained 1 year of high quality of life.

The mechanism of OC-induced remission of symptoms in patients with glucagonoma is still unclear. Certainly the sustained suppression of glucagon plasma levels compared to pretreatment concentrations plays an important role. Nevertheless, during therapy glucagon plasma levels are still elevated, in our patient exceeding the upper normal limit tenfold, and glucagon plasma concentrations rose despite continuous treatment with OC. Glucagon immunoreactivity is heterogeneous in human plasma $[11,12,26]$. In addition to glucagon, plasma of normal subjects and of patients with glucagonoma contains proglucagon $[6,7,11,12,19$, $24,25,28,29]$, a 9000-dalton protein devoid of glucagon bioactivity [20] formerly termed "large" glucagon immunoreactivity, and preproglucagon (a 180 amino acid protein) $[12,24,25,28]$ previously referred to as "big" plasma glucagon, which all cross-react with the anti-glucagon antibody K30 $[27,29]$ specific for the carboxyl-terminal region of glucagon [2]. In the present study determination of IRG in plasma subjected to gel chromatography clearly revealed three distinct immunoreactive glucagon species in the molecular weight range of 3500,9000 , and larger than 13000 daltons, resembling glucagon, preglucagon, and preproglucagon, respectively. During therapy with $O C$ a considerable shift from 3500-dalton glucagon towards preproglucagon was observed. Therefore, we speculate that $\mathrm{OC}$ inhibits preferentially posttranslational conversion of biologically inactive high molecular weight precursors of glucagon to bioactive 3500dalton glucagon. Thus, determination of immunoreactive glucagon in plasma does not reflect the true suppression of bioactive glucagon. This explains the discrepancy between high plasma glucagon concentrations and the vanishing symptoms during $\mathrm{OC}$ therapy in our patient and other cases [22]. Furthermore, if somatostatin and its analogue $\mathrm{OC}$ interfere only with posttranslational processing of preproglucagon but do not inhibit gene expression, tumor proliferation might not be prevented, as was shown in this and other patients.

The slow but constant decrease in body weight clearly shows that $\mathrm{OC}$ is not able to reverse the 
catabolism. In addition to glucagon, which remains elevated during $\mathrm{OC}$ therapy, even when bioinactive precursors are accounted for, other factors might add to the catabolism. The weight loss may also be related to loose stools and steatorrhea induced by OC, which has been reported before [1]. In addition to suppression of pancreatic exocrine function [8], other factors such as reduced gastrointestinal resorption and splanchnic blood flow [16] appear to contribute to the steatorrhea, since it did not respond to orally administered pancreatic enzymes in our patient. Furthermore, hyperglycemia was worsened by OC, which is most likely due to suppression of insulin secretion (data not shown). Thus, less glucose is metabolized and more glucose lost with urine, enhancing the catabolism.

This is the first glucagonoma reported to secrete CGA [13]. CGA is produced by a variety of endocrine neoplasm or adenomas and has proven to be a useful marker for such tumors [23]. In our patient, serum CGA demonstrated better sensitivity in the reflection of tumor activity than plasma glucagon levels. Therefore CGA might be useful as an additional tumor marker in glucagonomas, especially when considering the change in plasma IRG induced by OC, which does not reflect true tumor activity but merely changing posttranslational processing of glucagon precursors.

Scintigraphy with labeled somatostatin has confirmed the location of the primary tumor in the pancreatic head and the presence of several metastases in the liver. Metastases at other locations were not detected by scintigraphy. With hindsight, this was confirmed by the clinical course, since no metastases were identified elsewhere. This adds further evidence to the usefulness of scintigraphy with labeled somatostatin or its analogue OC, especially when surgical reduction of tumor mass is being considered.

In summary, we conclude that $O C$ is a valuable therapy for quick relief of symptoms in patients with glucagonoma syndrome but does not prevent tumor growth. Furthermore, this investigation indicates that $O C$ inhibits posttranslational conversion of biologically glucagon precursors to bioactive glucagon.

Acknowledgements. We thank Prof. Roger H. Unger, University of Texas, Dallas, for the generous gift of the anti-glucagon antibody $30 \mathrm{~K}$. Skilled technical assistance by Miss G. Kelz is gratefully acknowledged.

\section{References}

1. Anderson JV, Bloom SR (1986) Neuroendocrine tumors of the gut: long-term therapy with the somatostatin analogue
SMS 201-995. Scand J Gastroenterol 21 [Suppl 119]: 115128

2. Assan R, Slusher N (1972) Structure/function and structure/ immunoreactivity relationships of the glucagon molecule and related synthetic peptides. Diabetes 21:843-855

3. Bakker WH, Albert R, Bruns C, Breeman WAP, Hofland LJ, Marbach P, Pless J, Pralet D, Stolz B, Koper JW, Lamberts SWJ, Visser TJ, Krenning EP (1991) [ [ ${ }^{111}$ In-DTPA-D-Phe $\left.{ }^{1}\right]$ Octreotide, a potential radiopharmaceutical for imaging of somatostatin receptor-positive tumors: synthesis, radiolabeling and in vitro validation. Life Sci 49:1583-1591

4. Bender H, Maier A, Wiedenmann B, O'Connor DT, Messner K, Schmidt-Gayk H (1992) Immunoluminometric assay of chromogranin $\mathrm{A}$ in serum with commercially available reagents. Clin Chem 38:2267-2272

5. Bloom SR, Polak JM (1987) Glucagonoma syndrome. Am J Med 82:25-36

6. Danforth DN, Triche T, Doppman JL, Beazley RM, Perrino PV, Recant L (1976) Elevated plasma proglucagon-like component with a glucagon-secreting tumor. $N$ Engl J Med 295:242-245

7. Fujita J, Seino Y, Ishida H, Taminato T, Matsukura S, Horio T, Imamura S, Naito A, Tobe T, Takahashi K, Midorikawa O, Imura H (1986) A functional study of a case of glucagonoma exhibiting typical glucagonoma syndrome. Cancer 570:860-865

8. Gorden P, Comi RJ, Maton PN, Go VLW (1989) Somatostatin and somatostatin analogue (SMS 201-995) in treatment of hormone-secreting tumors of the pituitary and gastrointestinal tract and non-neoplastic diseases of the gut. Ann Intern Med 110:35-50

9. Hallengren B, Dymling JF, Manhem P, Tennvall L, Tibblin S (kk1983) Unsuccessful DTIC treatment of a patient with glucagonoma syndrome. Acta Med Scand 213:317318

10. Harris V, Faloona GR, Unger RH (1979) Glucagon. In: Jaffe BM, Behrmann HR (eds) Methods of hormone radioimmunoassay. Academic Press, New York, pp 643-656

11. Holst JJ (1983) Molecular heterogeneity of glucagon in normal subjects and in patients with glucagon-producing tumors. Diabetol 24:359-365

12. Jaspan J, Rubenstein AH (1977) Circulating glucagon. Diabetes 26:887-902

13. Jockenhövel F, Reinwein D (1992) Das Glukagonom: klinische Aspekte, Diagnostik und Therapie. Aktuel Endokrinol 13:66-80

14. Karnofsky DA, Burchenal JH (1949) The clinical evaluation of chemotherapeutic agents. In: McLeod MA (ed) Evaluation of chemotherapeutic agents. Columbia University Press, New York, pp 191-205

15. Krenning EP, Bakker WH, Kooij PPM, Breeman WAP, Oei HY, de Jong M, Reubi JC, Visser TJ, Bruns C, Kwekkeboom DJ, Reijs AEM, van Hagen PM, Koper JW, Lamberts SWJ (1992) Somatostatin receptor scintigraphy with indium-111DTPA-D-Phe-1-octreotide in man: metabolism, dosimetry and comparison with iodine-123-Tyr-3-octreotide. J Nucl Med 33:652-658

16. Lucey MR, Yamada T (1989) Biochemistry and physiology of gastrointestinal somatostatin. Dig Dis Sci 34:5S-13S

17. Maton PN, Gardner JD, Jensen RT (1989) Use of long-acting somatostatin analog SMS 201-995 in patients with pancreatic islet cell tumors. Dig Dis Sci 34:28S-35S

18. Moertel CG, Lefkopoulo M, Lipsitz S, Hahn RG, Klaassen D (1992) Streptozocin-doxorubucin, streptozocin-fluorouracil, or chlorozoticin in the treatment of advanced islet-cell carcinoma. N Engl J Med 326:519-523

19. Recant L, Perrino PV, Bhathena SJ, Danforth DN, lavine 
RL (1976) Plasma immunoreactive glucagon fractions in four cases of glucagonoma: increased "large glucagon-immunoreactivity." Diabetologia 12:319-326

20. Rigopoulou D, Valverde I, Marco J, Faloona GR, Unger RH (1970) Large glucagon immunoreactivity in extracts of pancreas. J Biol Chem 245:496-501

21. Rosenbaum A, Flourie B, Chagnon S, Blery M, Modigliani R (1989) Octreotide (SMS 201-995) in the treatment of metastatic glucagonoma: report of one case and review of the literature. Digestion 42:116-120

22. Santangelo WC, Unger RH, Orci L, Dueno MI, Popina JJ, Krejs GJ (1986) Somatostatin analog-induced remission of necrolytic migratory erythema without changes in plasma glucagon concentration. Pancreas 1:464-469

23. Sobol RE, Memoli V, Deftos LJ (1989) Hormone-negative, chromogranin A positive endocrine tumors. N Engl J Med $320: 444-447$

24. Tanaka K, Watabe T, Shimizu N, Horiuchi T, Nakamura K, Yoshida H (1984) Immunologic characterization of plasma glucagon components in a patient with malignant glucagonoma. Metabolism 33:728-733
25. Valverde I, Lemon HM, Kessinger A, Unger RH (1976) Distribution of plasma glucagon immunoreactivity in a patient with suspected glucagonoma. J Clin Endocrinol Metab 42:804-808

26. Valverde I, Villanueva ML, Lozano I, Marco J (1974) Presence of glucagon immunoreactivity in the globulin fraction of human plasma ("big plasma glucagon"). J Clin Endocrinol Metab 39:1090-1098

27. von Schenck H, Nilsson OR (1981) Radioimmunoassay of extracted glucagon compared with three non-extracted assays. Clin Chim Acta 109:183-191

28. von Schenck H, Thorell JI, Berg J, Bojs G, Dymling JF, Hallengren B, Ljungberg O, Tibblin S (1979) Metabolic studies and glucagon gel filtration pattern before and after surgery in a case of glucagonoma syndrome. Acta Med Scand 205:155-162

29. Weir GC, Horton ES, Aoki TT, Slovik D, Jaspan J, Rubenstein AH (1977) Secretion by glucagonomas of a possible glucagon precursor. J Clin Invest 59:325-330

30. Williams G, Anderson JV, Williams SJ, Bloom SR (1987) Clinical evaluation of SMS 201-995. Acta Endocrinol 116 [Suppl] 286:26-36 